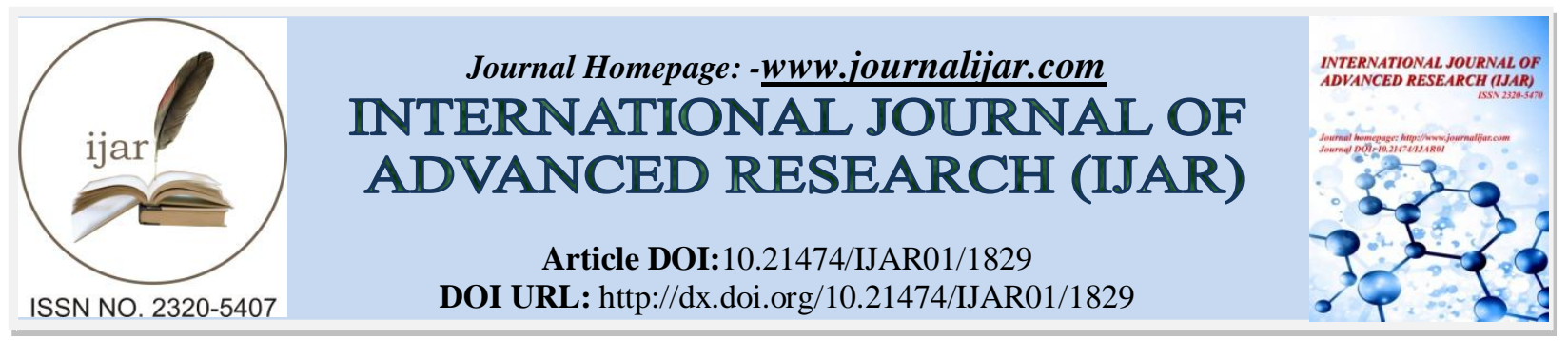

RESEARCH ARTICLE

\title{
FACTORS AFFECTING CHOICE OF PHYSICIANS RELATED TO LIFESTYLE DISEASES.
}

\author{
Sagar Teli*, S. Sowmya Celestina, Foram Patel, Kanjani Shah, Nayan Joshi, Riddhi Desai and Haresh \\ Raulgaonkar.
}

Shobhaben Pratapbhai Patel School of Pharmacy \& Technology Management,SVKM's NMIMS, Vile Parle, Mumbai.

\section{Manuscript Info}

\section{Manuscript History}

Received: 12 August 2016

Final Accepted: 23 September 2016

Published: October 2016

\section{Key words:-}

Consumer behavior; perceived value, primary care, decision making, Factor Analysis

\section{Abstract}

The relative importance that consumers attach to various factors in choosing a primary care doctor (PCD) for lifestyle related diseases were analyzed in a cross-sectional, survey. Survey participants included a heterogeneous mix of age, profession, and educational and geographical backgrounds. Participants rated the importance of the 16 items and a total of 258 responses were recorded and used for analysis.Demographic questionnaires were also administered to the participants. As per the results of the survey, participants perceived professionally relevant factors (e.g. whether the doctor is skilled and experienced), the convenience for medication (e.g. waiting time, fees structure), suggestions from chemist and appearance of the doctoras important factors. Participants' own characteristics and demographics held little relationship with the perceived importance of doctor characteristics. Factors that theparticipants perceive as most important to their choice of a PCD are also those that have the greatest effect on the quality of healthcare that they will receive. All the choices are made based on perceived value. A better understanding of the factors that influence people's choice of a PCD can contribute in understanding the trends for lifestyle diseases and consumer behavior attitudes towards PCD

Copy Right, IJAR, 2016,. All rights reserved.

\section{Introduction: -}

Research on medical choices or preferences has concentrated more on the decision-making abilities of medical practitioners than those of patients ${ }^{[1,2]}$. For example, research has addressed the extent to which diagnosticians' judgments are influenced by knowledge of the correct or the manner in which diagnostic alternatives are presented [3]. Some attention has been paid as well to patients' decision making. Patients, like doctors, are influenced by a variety of factors related to healthcare decisions ${ }^{[4]}$.

Relatively little research has addressed one of the first decisions that patients must make; that is, the choice of a doctor. In a country like India where the social health schemes are not provided to patients and all health expenses are made out of the pocket, patients are cautious regarding selection of a doctor especially when it comes to lifestyle related diseases. Being a multicultural diversified country, various parameters are taken into consideration starting with the basics like age, sex, appearance, qualification, religion, and approach towards treating the patients which play a primary role as when in patients choosing a doctor. 
In a more urban environment the major parameters for choosing or rejecting a doctor depend on his record such as incidents of malpractices, office hours, time given to each patient, doctors making further recommendations, fee of treatment by a healthcare provider etc. In both rural and urban scenarios, the major points that countare the word of mouth and the approach of the doctor towards handling patients. Generally, in India, it is observed that patients tend to skip doctors who recommend multiple visits if they are not comfortable or if it is inconvenient for them. In this conducted study, respondents' view is gauged through primary research which helps in highlighting and analyzing the factors that patients consider while selecting a doctor or rejecting one. The study gives a picture of the attitude and perception of patients towards doctors, their qualification and approach.

Also, the study shows how patients gather information about a doctor, through various touch-points like referrals about a doctor, which keep patients informed. The new generation electronic users also prefer doctors who themselves are techno savvy and keep in touch with the patients through various mediums of electronic media, mobile phone apps also are considered but usually only in the process of gaining basic information about a doctor. A better understanding of the factors that influence people's choice of healthcare providers would potentially provide them with the resources to make better choices in this arena and attain great levels of satisfaction with their health status ${ }^{[5]}$.

\section{Literature Review: -}

Literature review was done in order to analyze the nature and scope of previously conducted studies in this area. A study was conducted which identified following factors influencing patient's choice in descending order of magnitude: nearness, quality of service, finance, ease of transport and religion. A further study stated that the probability of selection of a healthcare provider is positively related to characteristics of patients as well as healthcare providers. Few more researches have explored that patients' choice with respect to a healthcare provider is driven by location, service provision, and reputation. A research study also found availability \& affordability of drugs, geographical accessibility to the facility and appropriate opening hours has impact on choice. Another study stated physician's advice as an important factor. It is also stated that, along with other factors, patient's demographic factors have impact on his choice. Other studies stated that, experience is found to be most important followed by referral by a general practitioner, certified quality management system, positive press coverage, recommendation by relatives \& acquaintances and distance to the hospital, reception area design, the personnel's friendliness, the website quality and the published quality report are less relevant. A study also stated factors like quality of the medical, distance to the hospital, amount paid at the initial visit, amount paid at hospitalization for examinations, and the organizational form of the hospital also have influence on patients' choice. On the basis of past review of literature, various factors influencing patient's choice were identified. Patients choice of healthcare provider is driven by various factors such as, accessibility, opening hours of the doctor's clinic, distance from clinic of healthcare provider, experience of patient, perceived overall reputation of doctor, reference by general practitioner, relatives and acquaintance, etc. Most of the studies stated that, along with these factors, demographic characteristics of respondent are also responsible for affecting the thought of consumer while they choose the doctor.

\section{Methodology: -}

The study was conducted with a sample consisting of varying age groups of participants. The questionnaire was prepared considering the factors to be analyzed while selecting a doctor for treatment of lifestyle diseases. The factors which were enlisted helped understand the patient's choice of a doctor for primary health care. Survey questions were drawn from previous studies (Bornstein \& Marcus 2000, Gopichandran et al 2013, PushkarDube et al, 2013). The questionnaire was then circulated through the sample selected through random sampling. Surveys were restricted to people over 20 years of age. A Likert scale of 1 to 5 was used to determine the importance of each factors while choosing a doctor, with 1-strongly disagree/least important and 5-strongly agree/most important. Parameters like age, gender of the participant, monthly income and number of visits in past year were asked to understand the influence of these on the factors deciding the choice of doctor. Preliminary instructions regarding the survey were given to the participants post which they were requested to rate the factors/parameters which, in their opinion, were of importance to them while considering and selecting a doctor. Participants then rated the importance of 16 predetermined items. Post the survey, participants were requested to fill in a brief demographic questionnaire. Data analysis was done by the means of SPSS Version 21. Reliability and validity test were made taking 17 different items by KaiserMeyer-Olkin $(\mathrm{KMO}=0.789)$ test was conducted to find the adequacy of sample. In order to draw meaningful inference from the study factor analysis technique was used. Factor analysis was used for data reduction so as to identify most important factors which have significance in the study. Principle component analysis was the 
approach used in factor analysis which considers the total variance in the data. It determines the minimum number of factors which will accumulate maximum variance in the data. Varimax method was used for rotation in the study, which maximizes the numbers of variable with high loading on a factor, enhancing the interpretability of factors.

\section{Results: -}

Sample characteristics: -

Table no.1 shows the breakdown of the sample characteristics. As the figures indicate, the sample was quite heterogeneous; participants came from a variety of age, profession, and educational, geographical backgrounds.

Table 1:- Sample characteristics.

\begin{tabular}{|c|c|}
\hline Characteristic & Percent Response \\
\hline $\begin{array}{l}\text { Gender: } \\
\text { Male } \\
\text { Female }\end{array}$ & $\begin{array}{l}50 \% \\
50 \%\end{array}$ \\
\hline $\begin{array}{l}\text { Age: } \\
20-30 \mathrm{yrs} \\
30-40 \text { yrs } \\
40-50 \mathrm{yrs} \\
50 \text { and above }\end{array}$ & $\begin{array}{c}60 \% \\
17 \% \\
10 \% \\
7 \% \\
\end{array}$ \\
\hline $\begin{array}{l}\text { Education: } \\
\text { High school } \\
\text { Junior College } \\
\text { Graduate } \\
\text { Post Graduate }\end{array}$ & $\begin{array}{l}12 \% \\
44 \% \\
50 \%\end{array}$ \\
\hline $\begin{array}{l}\text { Monthly Income: } \\
\text { Below 20000 } \\
\text { Rs20001-30000 } \\
\text { Rs30001-40000 } \\
\text { Above 40001 }\end{array}$ & $\begin{array}{l}42 \% \\
15 \% \\
12 \% \\
31 \% \\
\end{array}$ \\
\hline $\begin{array}{l}\text { Profession: } \\
\text { Student } \\
\text { Service } \\
\text { Home maker } \\
\text { Business } \\
\text { Other }\end{array}$ & $\begin{array}{c}35 \% \\
31 \% \\
9 \% \\
13 \% \\
12 \%\end{array}$ \\
\hline $\begin{array}{l}\text { Marital Status: } \\
\text { Single } \\
\text { Married }\end{array}$ & $\begin{array}{l}60 \% \\
40 \%\end{array}$ \\
\hline $\begin{array}{l}\text { Number of Visits to doctors: } \\
\text { None } \\
1-5 \\
6-10 \\
>10\end{array}$ & $\begin{array}{l}9 \% \\
68 \% \\
12 \% \\
11 \%\end{array}$ \\
\hline
\end{tabular}

The frequency of visiting doctors was moderately high. Nearly three-quarters of participants (68\%) had made one to five visits in the past year; the remainder was roughly split between those who had visited their doctors six or more times and those who had not been to their doctors at all. The sample largely consisted of students (35\%), and working professionals $(31 \%)$.

\section{Factors under consideration in PCD choice: -}

The variable that participants deemed most important to their choice of a PCD was the skill and experience of the doctor. In general, variables relating to the doctor's professional expertise (e.g. expertise, experience) were rated highly, while other factors relating to the doctor's individual characteristics, aesthetics, and proximity of the clinic were considered relatively unimportant. 
An exploratory factor analysis by Varimax with Kaiser Normalization rotation method was performed to identify the probable underlying factors. The best model, which explained $52.96 \%$ of the variance, contained four factors with Eigenvalues greater than 1.0 (Table 2).

Table 2:- Total variance explained.

\begin{tabular}{|c|c|c|c|c|c|}
\hline \multirow[b]{2}{*}{ Component } & \multicolumn{3}{|c|}{ Initial Eigenvalues } & \multicolumn{2}{|c|}{ Extraction Sums of Squared } \\
\hline & Total & $\begin{array}{c}\% \text { of } \\
\text { Variance }\end{array}$ & $\begin{array}{c}\text { Cumulative } \\
\%\end{array}$ & Total & $\%$ of Variance \\
\hline 1 & 3.515 & 25.107 & 25.107 & 3.515 & 25.107 \\
\hline 2 & 1.615 & 11.537 & 36.644 & 1.615 & 11.537 \\
\hline 3 & 1.230 & 8.789 & 45.432 & 1.230 & 8.789 \\
\hline 4 & 1.055 & 7.535 & 52.967 & 1.055 & 7.535 \\
\hline 5 & .980 & 6.998 & 59.965 & & \\
\hline 6 & .893 & 6.382 & 66.347 & & \\
\hline 7 & .827 & 5.908 & 72.255 & & \\
\hline 8 & .695 & 4.968 & 77.223 & & \\
\hline 9 & .651 & 4.647 & 81.870 & & \\
\hline 10 & .591 & 4.221 & 86.091 & & \\
\hline 11 & .556 & 3.968 & 90.059 & & \\
\hline 1 & .515 & 3.678 & 93.737 & & \\
\hline 13 & .483 & 3.450 & 97.187 & & \\
\hline 14 & .394 & 2.813 & 100.000 & & \\
\hline
\end{tabular}

Overall, the results of the factor analysis suggest that the majority of items did tap into underlying variables, reflective of four different aspects relevant to the choice of a PCD: Professional and interpersonal skill of the physician, Convenience of the patient, Chemist and Appearance of the doctor.

Table 3:- Rotated Component Matrix.

\begin{tabular}{|l|c|c|c|c|}
\hline \multirow{2}{*}{} & \multicolumn{3}{|c|}{ Component } \\
\cline { 2 - 5 } & 1 & 2 & 3 & 4 \\
\hline Proximity & .019 & .643 & .092 & -.222 \\
\hline Online & .107 & .130 & .588 & .000 \\
\hline Chemist & -.039 & .074 & .738 & .053 \\
\hline Experienced & .694 & .174 & .042 & -.149 \\
\hline Waiting time & .163 & .662 & .103 & .257 \\
\hline Foreign degree & .036 & .129 & .647 & .162 \\
\hline Friends family & .438 & .057 & .368 & .326 \\
\hline Fee & .051 & .705 & .066 & .262 \\
\hline Evening time & .202 & .620 & .214 & .118 \\
\hline Appear doctor & .028 & .142 & .190 & .759 \\
\hline Appear office & .382 & .182 & .013 & .627 \\
\hline Judgmental & .681 & .073 & .024 & .208 \\
\hline Explain illness & .799 & .098 & -.051 & .099 \\
\hline Technological advanced & .677 & .055 & .180 & .326 \\
\hline
\end{tabular}

Elements comprising of the professional skill factor were:experience of the doctor, diagnosis ability and ease of explaining a disease. The second factor was made up of elements like waiting time and doctors' fee. The third factor is the word of chemist and appearance of the doctor comprises of the fourth factor. 
Table 4:- Factor Analysis

\begin{tabular}{|l|l|c|l|c|}
\hline \multicolumn{5}{|c|}{ Factor Analysis } \\
\hline & $\begin{array}{c}\text { PROFESSION } \\
\text { AL SKILLS } \\
\text { OF THE PATIENT, }\end{array}$ & CHEMIST & $\begin{array}{c}\text { APPERANCE } \\
\text { OF DOCTOR }\end{array}$ \\
\hline Proximity & & & & \\
\hline Online & & & & \\
\hline Chemist & & & & \\
\hline Experienced & .694 & .738 & \\
\hline Waiting time & & & & \\
\hline Foreign degree & & & & \\
\hline Friend's family & & & & \\
\hline Fee & & & & .627 \\
\hline Evening time & & & & \\
\hline Appear doctor & & & & \\
\hline Appear office & & & & \\
\hline Judgmental & .798 & & & \\
\hline Explain illness & & & & \\
\hline $\begin{array}{l}\text { Technologically } \\
\text { advanced }\end{array}$ & & & & \\
\hline
\end{tabular}

\section{Discussion: -}

The present study shows results that indicate rationality of the respondents in the factors that they deem to be important in making a choice of a physician for lifestyle diseases. Factor analysis conducted brings to light that the following are the principal factors: professional \& interpersonal skills of the physician, convenience, chemist reference and appearance of the doctor (i.e. neatness). On the whole, respondents were most concerned about factors related to the skill of the doctor- both professional and interpersonal, followed by factors related to convenience to the respondent and chemists' referral while, the appearance of the doctor (i.e. neatness) was perceived to be the least important. When it comes to lifestyle diseases, even the educated patient population remains either unaware or partially/inadequately informed about the diseases and their management. It therefore, becomes important for them that the doctor explains various aspects of treatment and management with utmost patience. This is viewed as a function of experience of the doctor. The general perception is that the more experienced the doctor, the better the ability to explain aspects of treatment and disease management, which makes it the most important factor in consideration. Importance of other aspects such as the fee of doctor consultation, proximity of the doctor's clinic/hospital and waiting time at the doctor's clinic/ hospital indicate that the factor of convenience is a close second. Lifestyle diseases, at its core, have seen their advent due to busy lifestyle and associated stress; this implies that the patients would be unwilling to wait for longer periods for doctor consultation. Fee is another important consideration as lifestyle diseases require repeated or periodic visitations. This, concomitantly, is also the reason why proximity plays such an important role in making a decision. Therefore, convenience to the patient constitutes an important factor. In a country such as India, the chemist not only plays the role of a dispenser or medicines and retailer but also as the sole relatable and convenient touch-point. The local chemist acts as a reference point for most people, especially those that are new to a certain locality, to gain information about the doctors in the area. In addition, people of the lower socio-economic class find the chemist as a relatable entity and take basic healthcare advice from them for minor ailments, making them a trustable source of information. This makes the chemists' referral a factor of consideration to certain populations. The appearance of the doctor (i.e. neatness) is not deemed to be a very important factor as more importance is given to experience and skill of the doctor. This makes the external factors of the doctor irrelevant to the decision making process. The most interesting find of this study was the low response towards use of online or mobile apps for search of doctors. Even though such apps claim to assist in this decision making process, when it comes to choosing a doctor to be associated for longer periods of time, such as in the case of diabetes etc., these portals are not the go-to option and in fact are not deemed very reliable. If these apps were promoted strongly and endorsed by doctors themselves or were promoted amongst the chemists/retailers, they may begin to gain more popularity leading to subsequent usage. 


\section{References: -}

1. Dawson N.V. \&Arkes H.R. (1987) Systematic errors in medical decision making: judgment limitations. Journal of General Internal Medicine 2, 183-187.

2. Detmer D.E., Fryback D.G. \&Gassner K. (1978) Heuristics and biases in medical decision-making. Journal of Medical Education 53, 682-683.

3. Arkes H.R., Wortmann R.L., Saville P.D. \&Harkness A.R. (1981) Hindsight bias among physicians weighing the likelihood of diagnoses. Journal of Applied Psychology 66, 252-254.

4. Mazur D.J. \& Hickam D.H. (1990) Treatment preferences of patients and physicians: influences of summary data when framing effects are controlled. Medical Decision Making 10, 2-5.

5. Hibbard J., Slovic P. \& Jewett J. (1997) Informing consumer decisions in health care: implications from decision-making research. Milbank Quarterly 75, 395- 413.

6. Factors influencing trust in doctors: a community segmentation strategy for quality improvement in healthcare, VijayaprasadGopichandran et.al, BMJ Open, Vol 2, Issue 12, 2013

7. Choosing a doctor: an exploratory study of factors influencing patients' choice of a primary care doctor, Brian H. Bornstein et al, Faculty Publications, Department of Psychology, University of Nebraska-Lincoln, 2000

8. Physician Assistant Specialty Choice: A Factor Analysis Karen A. Wright et al, The Journal of Physician Assistant Education, Vol 22 No 2, 2011

9. Factors Affecting Choice Of Hospital Services in Bilaspur City, PushkarDubey and Dr.Suhir Kumar Sharma, International Monthly Refereed Journal of Research In Management \& Technology, Vol 3, 2013 